\title{
Rights of Interior Decoration Designer "A study in Light of UAE Federal Law No. 7 of 2002 on the Protection of Copyright and Neighboring Rights"
}

\author{
Nada Zuhair Al - Feel ${ }^{1}$ \\ ${ }^{1}$ College of Law, University of Sharjah, UAE \\ Correspondence: Nada Zuhair Al - Feel, Associate Professor of Commercial Law, College of Law, University of \\ Sharjah, UAE. E-mail: nalfil@sharjah.ac.ae
}

Received: March 2, 2019

Accepted: March 14, 2019

Online Published: May 30, 2019

doi:10.5539/jpl.v12n2p61

URL: https://doi.org/10.5539/jpl.v12n2p61

\begin{abstract}
This study includes the answer to the question that may be raised regarding the possibility of considering the design of the interior decoration as classified as protected works in the UAE law, and the consequent enjoyment by the designer of the literary and financial rights of the author. Paragraph 11 of UAE Federal Law No. 7 of 2002 on the protection of copyright and related rights refers to the design of decoration as one of the examples of the technical works mentioned by the legislator. The answer to the questions raised in this study is divided into two axes: the first is the technical framework and guarantee the historical development of the design, the role of the Arab design in the development of the design of the decoration and the definition of the designer and distinguish it from the architectural design. The second axis included the legal framework and included the conditions that must be met in the decoration design in order to enjoy legal protection, the rights of the decorator and then the legal protection of the right of the decorator.
\end{abstract}

\section{Introduction}

\subsection{Importance of Study}

Design has played a significant role in the life of mankind, as we find it in all the details of an individual's life. The designer in his community has become the link between the individual and his life requirements. Following every part of the creative works in the design exhibitions reveals that this is not arbitrary or accidently which means that the designer has the creative personality that can take into account the elements of beauty, usefulness, functionality and environmental conditions. ${ }^{1}$

The UAE has taken an interest in interior design as the interior design companies and offices have become a strong driver for the country's economy ${ }^{2}$. The market for interior equipment and designs in 2014 has generated AED 9.9 billion, which represents (35.5\% of the Gulf's interior equipment and interior design market) and approximately AED 34 billion in internal equipment and interior design in the same year. UAE is among the first Middle East countries in terms of the number of registered buildings under (LEED) and has 802 building, versus 1,250 buildings in the whole region. ${ }^{3}$

\subsection{Problem of the Study}

In spite of the previous data, and in spite that the design of decoration is an extension of the architectural design there is no good decoration unless preceded by good architecture and construction - where the designer can combine the functions of interior design and architectural design, and that the relationship between these two designs is very close. It is clear that UAE legislator is interested in architectural design but not interior design or decoration design. Paragraph (2) of article 11, of the Federal Law No. 7 of 2002 on the Protection of Copyright and Neighboring rights, the legislator has indicated (architectural designs ) but ignored decoration designs as one

\footnotetext{
${ }^{1}$ See Mohammed Al-Muneef, Art Stations - Design Arts combine utilitarianism and aesthetics, article published in Al-Jazirah Newspaper, No. 476, 31/10/2015, available on the website: http: // www.al-jazirah.comlcultureL2015 Date of visit 7/13/2016

2 Interior Design in UAE: https://adplan.ae/varieties

${ }^{3}$ LEED, a system that provides accreditation in energy and environmental design - see Al Bayan Economic Newspaper, 2/2/2014 available at: www.albayan.ae/economy/discussion/2014-11- Date of visit 5/2/2019
} 
of the works which authors have legal protection.

Because design reflects a mental product reflecting the creativity of the designer, it was necessary to pose a question whether it can be classified as a protected work in UAE law if the requirements of such protection are met?. Is it possible to take advantage of the attitude of the UAE legislator to mention works of art, for example, without classifying their types, because of the diversity of these works resulting from the diversity of the arts and the multiple means of expression? The French judiciary has included decorating and painting works in protection as long as it contains an original innovation, etc. ${ }^{4}$ If design can be considered as a publication, what are the rights of the Interior decoration designer?

\section{Methodology}

The study has applied the descriptive approach, in order to give a clear conception of the design of the decoration; its definition, the history of its emergence, the definition of the designer and the conditions that must be met in the design of the decoration in order to enjoy the legal protection and the rights of the decorator .

The study has applied the deductive approach, where the provisions of the law relating to the author and the art works provided by the UAE legislator was applied in Federal Law No. 7 of 2002 on the protection of copyright and Neighboring rights, in particular with respect to architectural designs not mentioned by the legislator nor covered by legal protection.

It should be noted that a very important issue before going into the details of the research is that although the interior design is more inclusive than Interior Decoration, but the confusion between them is common; they follow the same sector and both of them mean the final output of the decoration and rendering beauty and deal with the same concepts, and some name Interior Design as Interior Decoration, both of which have the same function. ${ }^{5}$ Also, Webster dictionary defines interior design as: the art or practice of planning and supervising the design and execution of architectural interiors and their furnishings), and when searching for the meaning of the word (decoration) in the same dictionary; it directs us to see the meaning of "interior design". 6

\section{First Axis / Technical Framework}

It includes the historical development of interior decoration design (interior design), the design profession, and the role of Arab designer in the development of interior decoration or interior design, the definition of the designer,and how is he distinguished from the architecture. This axis is divided into the following paragraphs:

\section{First - the historical development of interior design (decoration design).}

The interior design as part of the construction process dates back to ancient period of history. The interior design profession has emerged as a result of the development of society and the complex structure that resulted from industrial development, and contributed to the effective use of space and the welfare of users, and career design in the development of this profession.

Interior design is separate and distinct from the role of interior, a term commonly used in the United States. This term is less common in the UK, as the interior design profession is still disorganized and, strictly speaking, is no longer a formal profession. ${ }^{7}$

One of the most influential theorists of the $19^{\text {th }}$ century, Owen Jones was a central figure in the propagation of interior design theories to the middle class. Jones's first project was his most important project in 1851, where he was responsible not only for the decoration of the Paxton's Crystal Palace, but also was responsible for the exhibits inside. He chose a controversial panel of red, yellow and blue to make the inner iron. One of his most important publications was Grammar of Ornament (1856). ${ }^{8}$

\footnotetext{
${ }^{4}$ Prof.Abdul Rashid Mamoun, d. Mohamed Sami Abdel-Sadiq, Copyrights and Neighboring Rights (in light of the new Law on the Protection of Intellectual Property Rights No. 82 of 2002), Dar Al-Nahda Al-Arabiya, 2004, p.

${ }^{5}$ Heba El Gjundy, The Difference Between Interior Design and Interior Decoration, Article available at: http: // weziwezi.com

${ }^{6}$ See the difference between interior decoration and interior design - Sarh Consulting, article available at: http: // en-ar. facebook- com / sarhconsult / posts.

${ }^{7}$ Blakemore, R.G(2006). History of Interior Design Furniture: From Ancient Egypt to Nineteenth-Century Europe. J. Wiley, p. 4.

${ }^{8}$ Clouse, Doug(2009). "The Handy Book of Artistic Printing: Collection of Letterpress Examples with Specimens of Type, Ornament, Corner Fills, Borders, Twisters, Wrinklers, and other Freaks of Fancy". Princeton Architectural Press,. p. 66.

In 1882, the London Post Office Directory registered a list of 80 interior decorators. Some of the most prominent companies in this period were Crace, Waring \& Gillowm, and Holland \& Sons. Among the famous figures hired by these companies were Thomas Edward Colcott, Edward William Goodwin, Charles Barry, Gotfried Simper and George Edmond Street. Please see:
} 
The interior design profession became more established after the Second World War; 1950 has witnessed an increase in house spending, interior design courses were delivered for interior designers and companies distinguished from decorative arts professionals, and organizations were established to regulate education, qualifications, standards and practices, and all that led to the development of the profession. The American Society of Interior Designers (ASID) was established in 1957, while in the UK the Interior Decorators and Designers Association was established in 1966. Across Europe, other organizations such as The Finnish Association of Interior Architects (1949) were being established and in 1994 the International Interior Design Association was founded. ${ }^{9}$

\section{Second: The role of design in the development of design of decoration.}

Arabic design contributed to the development of interior design. The term "painting", also called nagash, is the decoration of "Al-Majles", or the guest room of traditional Arab houses, in the Asir region of Saudi Arabia and the neighboring parts of Yemen. These frescoes appear as arabesque or Fresco and are called Niqash in Arabic, which represent a woman in her house. ${ }^{10}$

It seems that the architectural designs and lines adapt to the building patterns throughout the Arabian Peninsula. The decorative color and decorations characterize Asir region and the painting may extend to the house on the walls and doors, above the stairs, and on the furniture itself. When drawings are made, women assist in such work. Work is shared by a large group of employees. This work is based on the straight lines design and suggests common patterns of interior design, with solid lines of different colors showing certain motifs, such as the triangular (prayer) niche or the "mihrab" and the "palm" in the past. The paint was produced from metallic coloring pigments and vegetables, such as cloves and green clover, while the blue color was extracted from of the indigo plant. The red color was extracted from pomegranate and special clay. The coloring brush was constructed from the hard hair of the goats' tail. However, women use modern paint to create new shapes, which have become an indicator of social and economic change. ${ }^{11}$

Women in Asir region in Saudi Arabia often decorate and paint the house from inside. "If they do not have a lot of money, the wife can draw simple, straight lines in patterns three to six times, and women use other women to paint the walls themselves. Many Saudi women have become famous as painters. The yards and the corridors of the upper columns are the main features of the best architectural design known as the 'nadd design', in addition to the jiss and the painted windows shutters, which Beautify the quest rooms, around the coffee fireplace and along the walls above the carpets and on the pillows. The patterns of the painters of Najd differ from the painters of eastern region of Saudi Arabia, Oman and the ancient Mesopotamia. Flowers, stars, triangles, and the dadoes pattern are all old patterns, and can be found throughout the Middle East in ancient times. It seems that the Qassim area is the origin of this art. In Riyadh, examples can be seen in uncoated mud. ${ }^{12}$

In Egypt, interior design has been known for 5000 years in the time of Egypt's pharaohs, who were known for their love for decoration and colors. They had concern with the finest details in the giant doors, high walls, high ceilings and huge ornamented pillars. The decorations were painted in bright colors such as yellow, blue and red to adorn the place. The golden color was their symbol, but did the decoration mean spiritual meaning? Of course not, because they did not intend to pay attention to the interaction of the place with people and their daily requirements, but their aim was to parade their rich palaces and that was their social law. ${ }^{13}$

This phenomenon continued throughout the ages until the $18^{\text {th }}$ century when the factories emerged and facilitated the production of furniture more quickly because they produced one template for the design required and then replicated by the machine itself. Before that, a piece was produced by skilled craftsmen. This process took many hours and needed high skills to make the furniture designed with excellent craftsmanship and mastery by the middle class workers in the society. The poor and medium classes of society tended to pay attention to the quality of production rather than to the dazzling appearance. The decor was influenced by all the conditions of the society negatively and positively and reflected the richness of society without paying attention to the interaction of human spirit with the place in which it lives. The whole attention was to the furniture, and then

Clive Edwards (2005). Turning Houses Into Homes: A History of the Retailing and Consumption of Domestic Furnishings. Ashgate Publishing, Ltd. Retrieved 2013-02-07.https: //books.google.jo/books? Id = WcLc

${ }^{9}$ Lees-Maffei, G, 2008, Introduction: Professionalization as a focus in Interior Design History, Journal of Design History, Vol. 21 , p. 1.

${ }^{10}$ Yunis, Alia, "The Majlis Painters," Saudi Aramco World Magazine, July/August 2013, pages 24-31

${ }^{11}$ Maha Al Faisal and Khalid Azzam. 1999. "Doors of the Kingdom" Saudi Aramco World. This article appeared on pages 68-77 of the January/February 1999 print edition of Saudi Aramco World\# http://www.saudiaramcoworld.com/issue/199901

${ }^{12}$ - Mostyn, Trevor. 1983. Saudi Arabia. London: Middle East Economic Digest. Pages 257-258

${ }^{13}$ See the difference between interior design and decoration design, article available on the website: http: // www.traident.net 
people paid attention to the importance of the use of furniture in various ways to benefit from them. The fact is that the attention to furniture as a decorative element does not mean that the decoration is limited to houses, but its areas are very wide; there are mosques, places of worship, palaces, museums, restaurants, clubs, universities, hospitals, shops, offices and institutions. ${ }^{14}$

\section{Definition of interior design}

The interior design is defined as: - (an innovative and creative process on which a person works to find a new and useful object) and the definition suggests two stages of access to interior design or decoration; the innovative stage then the executive stage. ${ }^{15}$

It is also known as: (Total planning and design of internal spaces intended to harness the physical, spiritual and social needs of people, which in turn ensure the integrity of the building). ${ }^{16}$

(Ralph, P. and Wand ) described it as: "the use of a set of primitive components, meeting a set of requirements, subject to limitations to create a design, in the designer's working environment". ${ }^{17}$

some described it as: - (Planning and innovation based on specific architectural data and take this planning for existence and then implementation in all places and spaces, whatever the purposes of their uses and nature using different materials and colors, or) to address the appropriate solutions to all the difficulties in particular field of movement in the space and the ease of use of the furniture and equipment and make this space comfortable, quiet and have all conditions and aesthetic standards and methods of pleasure and joy. ${ }^{18}$

Modern decoration has become one of the basic elements of the civilizational form of any public or private institution. It is concerned with the details of the first impressions of the customers. This is carried out in accordance with international quality standards for interior design including all elements of aesthetic design and harmonious coordination between sensual and emotional elements and the creative outcomes of the various interior designs of space, where man lives and practices his daily activities of work, comfort, entertainment, etc. The design work of a place becomes more successful, the more active elements in it are found,taking into account good use of each element. ${ }^{19}$

\section{Definition of decoration designer}

The design of the decoration varies widely from one personality to another. It is linked to cultures, studies, abilities, customs and traditions inherited and acquired through experiences and techniques that ultimately depend on the creativity and innovation of the designer. The good design is the basis for any integrated artistic work which is the ability of the designer to adapt his culture and abilities in the service of interior design or decoration, and address some of the corresponding problems in terms of space or places of lighting and ventilation, which are considered as important factors in achieving the integrated unity of design. ${ }^{20}$

The designer is: "Anyone who devises paths of action that aim to change current attitudes to preferred positions". 21

The term interior designer suggests that there is a greater emphasis on planning, functional design and efficient use of space, compared to interior decorating. The interior designer in the final design can carry out projects that include the planning of the master plan for spaces within the building, as well as projects that require an understanding of technical problems such as the placement of windows, doors, acoustics, and lighting. ${ }^{22}$

Therefore, those who innovate interior design should be aware of all the architectural things, methods, techniques, materials in the implementation of interior design works, whether types of wall paints or their characteristics, as well as the use of colors and their interaction with each other, and the degree of color absorption and reflection of light, as well as ventilation holes and degree of control.

\footnotetext{
14 Samar Hassan Sukri, History of Interior Design, Rai Magazine, Issue 94, 4/8/2012, available on the website http: // magazine. islamtoday. net.

15 Mu'tasim Azmi Al-Karabiliya, Mohamed Saad Hassan, Introduction to Interior Design, Arab Society Library for Publishing, p.13

16 See Interior Design, Wikipedia Free Encyclopedia, http: // ar.wikipedia.org/wiki

${ }^{17}$ Ralph, P. and Wand, Y. (2009). "A proposal for a formal definition of the design concept". In Lyytinen, K., Loucopoulos, P., Mylopoulos, J., and Robinson, W., editors, Design Requirements Workshop (LNBIP 14), p. 109.

${ }_{18}$ See the basics of decoration, article available at: http: // en- ar.facebook.com

19 The definition of decoration is p. 1, an article available on the website http: // www. nouhworld. com / artice

20 (Interior design), article available on the website: - http: // www. abahe.co.uk/ terminologies-interior- design.html

${ }^{21}$ Simon, H.A. (1996) The sciences of the artificial, MIT Press, Cambridge, MA, USA. p. 111.

${ }^{22}$ Pile, J., 2003, Interior Design, 3rd edn, Pearson, New Jersey, USA. P. 4 et seq.
} 


\section{But can amateur be considered as interior designer?}

Designers can design aesthetic and artistic aspects of the place, because they do not pose a threat to the user's life, and the interior designer is supposed to have a certificate in the basics of applied arts and related operational areas and be specialized in decoration design,and to enjoy creative and specialized skills in the field of social and professional communication skills in terms of coordination with the concerned bodies of professionals and executives and shall have skills of design, management and implementation of the work project. ${ }^{23}$

The designer is an author who is the inventor of the work (decoration design), and mentions its name when he makes it when published as an author unless the evidence is otherwise. A nick name also is evidence, provided that he must have the evidence that he owns such design. But if there is a doubt in such ownership, such designer shall be considered as a publisher for such a work until the original owner is known. ${ }^{24}$ There are many companies to develop interior designs such as Vision Furniture \& Decoration Factory, The Home Decor Company in Dubai.

The decoration designer must take into consideration, when used, each element of interior design - form and floor, active elements (color and light), derived elements, utility, durability, economy, beauty). When he uses the lighting and electricity component, the lighting shall be distributed in a manner consistent with the furniture, taking into account the distribution of furniture in each room and the area of this room and, purpose of its use and the number of users of such room, the average age of users, the distribution of windows and doors and the way of movement, direction and distribution of electrical plugs, and to consider vision, external noise and so on.$^{25}$

\section{Fifth: Distinguishing interior design from architectural design.}

Architectural design is the biggest picture of the design. It is the design of the building's inherent mass; exterior facades, columns, walls, exits, entrances, lighting openings and annexes; the main division of the distribution of interior spaces such as rooms, bathrooms and kitchens, as well as external spaces and relation to the public site, external materials and construction; and the building to be safe to use.

The interior design is the most detailed. It is all the details of finishes, colors, texture, general atmosphere, interior and exterior lighting, furniture and interior distribution with a more detailed division. The interior designer may not be able to remove walls, make profound or radical changes in the mass. ${ }^{26}$

\section{Second axis / legal framework}

The focus is on the conditions that must be met in the design of the decoration in order to enjoy the legal protection, the moral and financial rights of the designer of the decoration and the legal protection of the rights of the designer, which differ whether the design is made individually or jointly by the designers, or was collectively made by more than one person under the guidance of a natural or legal person, in the following paragraphs.

\section{Third: The conditions that must be met in decoration design the in order to enjoy legal protection.}

Since the design of the decoration involves an innovative and inventive process as presented, and that the work includes all forms of intellectual creativity in the field of literature, arts and sciences ${ }^{27}$, can the decoration design be considered as one of the works covered by copyright protection? This question arises on the basis that this term - the term decoration design or interior design - is not mentioned explicitly in the artistic works provided by the UAE legislator?

\section{To answer this question, we can say that:}

1 - In order to describe interior design or decoration design as a "publication", it is necessary to meet two conditions:

The first condition / originality of decoration design, in the sense that this design is the invention of the designer himself and that it is not entirely taken from another work, and the originality of the design is probably

\footnotetext{
${ }^{23}$ Interior design and decoration, article available at: http: // astfeed.wordpress.com

${ }^{24}$ Article 1 / P5 of UAE Federal Law No. 7 of 2002 on the Protection of Copyright and Neighboring rights

${ }^{25}$ Decoration Enginee.. Multiple tasks,one result, the Middle East, Issue 11857, 16 / May / 2011, pp. 1-2, article available on the website:http: // archive.aawsat. com / details.as

${ }^{26}$ See the article (The difference between architecture, interior architecture and architectural design), available at https://ask.fm

${ }^{27}$ Prof. Nawaf Kanaan, Copyright, Contemporary Models of Copyright and its Means of Protection, Dar Al-Thaqafa Library, Amman, $3^{\text {rd }}$ edition, 2000, p 197.
} 
relative rather than absolute, meaning that the design of the decoration which is innovative in an era may become familiar in another era .Also, originality is not subject to novelty, which means that the designer creates a new design. It is also not subject to the technical merit of design. Every designer has his personal originality to express his design regardless of the idea. Two design engineers may share the same materials used in the design, but they differ in colors and paints and are distributed in a manner that reflects the distinctiveness and originality of each other. ${ }^{28}$ Also, the design must be new and has not been published by others and contains a new innovation. ${ }^{29}$

\section{The second condition / the design of the decoration shall be in a physical image that brings it into existence.}

A "publication" in order to enjoy legal protection, it must first appear in a physical manner by completing and expressing its elements definitively. ${ }^{30}$ This occurs when people are aware of this design sensibly or mentally whether by sight, hearing or touch - and this is what is achieved in the design of the decoration, which is in materials,raw materials, furniture, measurements, distribution in the inner space, and other things related to lighting, distribution, flowers, accessories needed for space, in addition to that this design is characterized by having direct personal contact. The designer tries through its design to meet the needs of the users. Second, publication must be innovative; interior design is determined by the content of the process of composition and innovation that collects elements of the environment and put them in a particular configuration to give something that has a function.

In this regard, it is possible to say that interior design can combine the appearance and the innovation. Planning and innovation are based on specific architectural data, and this planning is carried out in all places and spaces regardless of their purpose and character and in an affordable cost. ${ }^{31}$

2 - Interior decoration or design is one of the specialties of modernity era, and one of the fields of Applied Art. It interferes with the industrial design, graphic design and fashion design, which have reached every place where people live and practice a kind of daily life. It is an extension of the fine architectural design. ${ }^{32}$

They also include paintings, drawings, carvings, photographs. Graphic designs and industrial designs may have separate or overlapping laws. ${ }^{33}$

Therefore, it meets with the expressions of artistic works contained in (paragraphs 7, 8, 9 and 10 and part of paragraph 11 of the architectural design) of Article 2 of the Federal Law No. 7 of 2002 on Copyright and Neighboring rights. These forms are:

* Works of architecture, drawings and engineering drawings.

* Works of drawings in lines or in color, sculpture, engraving and printing on stone, fabrics, wood, metals and any similar works in the field of fine arts.

* Photographic works and the like.

* Works of applied and plastic art.

* Architectural designs and others.

3 - The UAE legislator's mentioning of artistic works, would have allowed us and by analogy to include the decoration design or interior design within these works and thus, it has the legal protection prescribed for them.

4 - A part of Egyptian legislation relies on the fact that the French judiciary expanded the extension of legal protection to other works of art in addition to the French law of 1957, which stipulated to protect all graphic arts and works of painting, sculpture and engraving - as long as these works include an original innovation, such as

\footnotetext{
${ }^{28}$ Prof. Nawaf Kanaan, op. Cit., Pp. 198-200.

${ }^{29}$ Simon, Stokes (2001). Art and copyright. Hart Publishing. pp. 48-49.

${ }^{30}$ Prof. Naser Mohammed Abdullah Sultan, Intellectual Property Rights (Copyright and Neighboring rights, Patents and Industrial Designs, Trademarks and Commercial Data - Study in the Light of the New UAE Law and the TRIPS Agreement), University Library, Sharjah, Ithraa Publishing and Distribution, Jordan, I, 2009, Pp. 38-39.

${ }^{31}$ Prof.. Abdul Rahman Al-Radadi, The Concept of Interior Design (Decoration Engineering), Al-Bina'a Magazine, Issue 96, p. 2, available at: http: // www.allhadeeqa.com/vb/gardens/g12674/

${ }^{32}$ Decoration Engineer: Multiple tasks,one result, the Middle East, No. 11857, 16 / May / 2011, ibid., Pp. 1-2.

33 - Peter K, Yu (2007). Intellectual Property and Information Wealth: Copyright and related rights. Greenwood Publishing Group. p. 346.
} 
decoration, painting, decorative designs, decorative sculpture, art drawings and medical science drawings. ${ }^{34}$

Based on the above, the decoration designer will enjoy the rights of the author decided by the UAE legislator in Article 5 of UAE Law No. 7 of 2002, namely financial right, moral right and legal protection for them:

Moral right: It focuses on the protection of the personality of the designer as the creator of the design of the decoration, and the protection of the design itself, which in this sense involves two aspects: the first is the respect of the character of the designer as creative, and protect the work as something of intrinsic value regardless of its designer. ${ }^{35}$ The moral right of the designer is characterized by:

- A permanent and non-temporary right for a certain period, and it remains throughout his life and after his death, which does not end and is not subject to limitation.

- A right of the author is not to be disposed of or to be seized; the moral right of the designer is similar to the rights associated with the person such as the fatherhood, childhood and kinship as stipulated by the Egyptian legislation. ${ }^{36}$

Personal rights generally have no financial value so creditors can't seize them to recover their debts. ${ }^{37}$

- The moral right is not transferable to the heirs of the designer; as the moral right is of the rights associated with the personality, and because of the disappearance of the personality to which they belong. This characteristic would create difficulty, because the privileges of the author's moral right are generally multiple, and no part of them can be transferred to the heirs, such as the author's right of design, or the right to modify the design or withdraw; such rights that can only be exercised by him as creator of the design. As for the other part of these privileges, it is possible to be transferred to the heirs of the designer; such as the right to defend the design and prevent the deletion of any of its parts or component because it preserves the designer's honor and reputation. ${ }^{38}$

The moral right of the designer includes a number of sub-rights which give rise to him. These represent privileges or powers that enable the designer to protect his personality expressed by his intellectual production embodied in the design of the decors. These privileges are:

The moral right of the designer includes a number of sub-rights which represent privileges or powers that enable the designer to protect his personality represented by his intellectual production embodied in the design of the decoration. These privileges are:

\section{The decoration designer has the right to publish the design for the first time:}

It is one of the most important powers of the author's moral right. It is only he who decides whether his work is capable of being published or unpublished and without the intervention of anyone, and he also determines the manner and date of such publication. ${ }^{39}$ The decision to publish the design is considered as the birth certificate of the design, according to which the designer acquires the "author" title and the design acquires the "publication" title. $^{40}$

The designer has the right to claim title of design in himself .He is entitled to claim that the design he created is his design and such design is delivered to the public together with his name, surname and scientific qualifications, whether published by himself or by others, and he shall have the right to announce his name to the public or to make it without a name. ${ }^{41}$

The right of the designer to name the design is not limited to the individual designer, but includes joint and collective designs; one of the designers involved in the design of a hospital, for example, may not announce the design under his name only and neglect the mention of the other designers, and this case the other designers shall have the right to include their names on the design and to claim compensation, as long as the design e was a

\footnotetext{
${ }^{34}$ Mohamed Sami Abdel-Sadiq, Copyrights and Neighboring Rights (in light of the new Law on the Protection of Intellectual Property Rights No. 82 of 2002), Dar Al-Nahda Al-Arabiya, 2004, p. 111.

${ }^{35}$ Prof.Nawaf Kanaan, op. Cit., P. 83.

${ }^{36}$ Prof. Abdul Razzaq Al-Sanhoury, Al-Fi-Sharh Al-QANOON Al-Madani, part 8, Right of Ownership, Dar al-Nahda al-Arabiya, Cairo, 1967, p. 408.

${ }^{37}$ Prof. Nawaf Kanaan, op. Cit., P. 87.

${ }^{38}$ Prof. Nawaf Kanaan, op. Cit., Pp.90-92

${ }^{39}$ Prof. Ali Sayed Kassem, Intellectual Property Rights in UAE Law - Comparative Study, Dar Al-Nahda Al-Arabiya, Cairo, $12^{\text {th }}$ edition, No Publication Year, p. 226

${ }^{40}$ See Prof. Suhail Hussein Al-Fatlawi, The Moral Copyright in Iraqi Law, Comparative Study, Freedom House, Baghdad, 1978, p. 85.

${ }^{41}$ Prof. Nawaf Kanaan, op. Cit., Pp.90-92
} 
result of their cooperation. ${ }^{42}$

The right of the designer to prevent any breach against his design "the right of respect". Because the design is an intellectual creativity that represents the personality of the author, any breach by others would lead to distortion or damage to his reputation and such breach gives him the right to defend his reputation and honor, ${ }^{43}$ and this right continues even after his death; heirs may defend the reputation of the author and act to prevent any distortion, misrepresentation or harm to the author's reputation.

The Ministry of Culture and Information of the United Arab Emirates protects this right in the absence of heirs to the designer, after the expiry of the period of legal protection prescribed for the financial right and the inclusion of the decoration design in Public property. ${ }^{44}$

The Emirati legislator decides the right of the designer to withdraw his work from being used if there are serious reasons for this. This includes if the designer shall find that the design no longer keeps up with the development of the decoration design globally, it no longer matches the tastes of the customers ; if it is no longer compatible for his artistic opinions, or that he gained after publishing it a new culture and abilities in the field of design that enables him to modify the design in a new manner that makes him more beautiful and robust, or if previous design may harm his reputation or his position as a designer. he withdrawal shall be effected by the competent court with the obligation to pay a fair compensation to the owner of the financial exploitation rights of the design within the period determined by the court and before the order of withdrawal. ${ }^{45}$

The designer alone may authorize the exploitation of the design in any way, especially through copying, including loading, electronic storage, alteration, modification, leasing or publishing through information networks, communication networks and other means.

The designer or his successor may transfer to other parties, whether natural person or legal person, some or all of the financial rights due to him in return or free of charge. This act shall be written and shall specify the right to be disposed with a statement of purpose and duration of exploitation and its place and the designer then shall not commit any act that may hinder such exploitation. ${ }^{46}$

The designer or his successor may receive cash or in kind return for the transfer of one or more rights of financial exploitation of the design on the basis of relative share in the revenue resulting from exploitation, and financial exploitation may be contracted on the basis of a sum of money or the combination of both. ${ }^{47}$ if it becomes apparent that this contract is unfair to the designer, or becomes the same for circumstances that occurred after the contract, the designer or his successor may resort to the competent court to request reconsideration of the value of the agreed amount. ${ }^{48}$

Financial right: It means the right of the designer as the owner of intellectual production to monopolize the exploitation of this production (decoration design), with the benefit or financial gain, during a certain period of time. This right is characterized by the following:

- Exclusive right which means to use the design financially for the benefit of the designer alone and no other person may directly obtain this right without prior consent from him or his successors. He has the right to transfer to others the right to exercise the rights of exploitation prescribed for him or some of such rights. Duration of exploitation of his work shall be determined. ${ }^{49}$

The means that can be used by the designer in the exploitation of his design are many, and have been cited by the Emarati legislator - like the other copyright laws and the Berne Convention - for example but not limited to, and the designer to choose what suits the nature of the design, including electronic download or storage, representation by any means, broadcasting, performance, public delivery, translation, modification, leasing, lending or publishing in any manner, including through computer or information networks or network machines and other means. ${ }^{50}$ Berne Convention for the Protection of Literary and Artistic Works of 1979 has mentioned

\footnotetext{
${ }^{42}$ Dr. Abdul Rashid Maamoon Shedid, The Moral Right of the Author, General Theory and its Applications, Dar Al-Nahda Al-Arabiya, Cairo, 1978, p. 424.

${ }^{43}$ Prof. Nawaf Kanaan, op. Cit., Pp.124-125

${ }^{44}$ Prof. Ali Sayed Kassem, op. Cit., P. 227

45 Article $5 / 4$ of the Federal Law No. 7 of 2002 on the Protection of Copyright and Neighboring rights.

${ }^{46}$ Article 9 of the Federal Law No. 7 of 2002 on the Protection of Copyright and Neighboring rights.

${ }^{47}$ Article 10 of the Federal Law No. 7 of 2002 on the Protection of Copyright and Neighboring rights.

${ }^{48}$ Article 11 of the Federal Law No. 7 of 2002 on the Protection of Copyright and Neighboring rights

49 Prof. Nawaf Kanaan, op. Cit., P. 129.

${ }^{50}$ Article 7 of the Federal Law No. 7 of 2002 on the Protection of Copyright and Neighboring rights.
} 
such means under a general provision covering existing and future means of exploitation, such as photocopying and copying on videotapes, films and microfilm, which is an attitude consistent with the technological development of telecommunications which had a great influence on the means of exploiting works of various kinds. $^{51}$

The designer can make use of his own work financially, and he may relinquish this right to others, whether paid or free of charge.

\section{But when does the right of the designer to take advantage of its design emerge?}

An opinion in this literature says that "The right to financial exploitation emerges upon the physical appearance of its work; it is an intangible intellectual production that cannot be used materially unless it is made available to the public, and the financial right is in-kind right gives the author direct power to make use of its work. ${ }^{52}$

- A temporary right in the sense that it ends with a period of time specified by the law, so that the exploitation of the work financially terminates, but design after the end of the period becomes of the intellectual heritage where it belongs to the public property. ${ }^{53}$

\section{Fifth. Legal protection of designers' right.}

The length of protection of decoration design varies according to the form it takes, as it can be:

Individual: If the designer is a natural or legal person, he expresses his ideas, skills and culture in directing the design. He alone has the moral and financial rights of the design, and no one else shares him such right ${ }^{54}$. The design of the decoration in this case has the legal protection along he designer's life and for 50 years after his death, beginning from the first calendar year of the date of death. ${ }^{55}$

Joint: The design of the decoration is a joint work if it is designed by more than one designer, whether it is possible to separate the work of each of them from the other (such as one of the designers to identify the architectural matters and techniques, and the other designer to determine the different materials in the implementation of decoration works, Colors and interaction of color walls, the degree of color absorption and reflection of the light, the observation of the natural light openings in the design areas as well as the ventilation openings and the degree of control. The work of the participating designers may not be separated from each other, as if all designers participate in all design elements. ${ }^{56}$ Joint design of decoration enjoy legal protection throughout the life of the designers, and then for a period of fifty years starting from the first calendar year until the date of the death of the last surviving designer. ${ }^{57}$

Collective: The design is collective when it is made by more than one person under the guidance of a natural or legal person, who undertakes to implement it in his name, under his supervision and management, integrating the work of the designers so that none of them can be separated from each other. The natural or legal person who directs and supervises the work is the decoration designer. ${ }^{58}$ An example includes that as the Ministry of Housing requests a group of designers to make under its guidance and supervision a design of furnished apartments within a residential housing complex, the design then is considered collective, and will have all the moral and financial rights, and the duration of design protection here shall be fifty years from the first calendar year following the publication of the design for the first time if the designer is a legal person. ${ }^{59}$

4. If the designer is a natural person, the period of legal protection for the design of shall extend for the life of the designer for a period of fifty years after his death, beginning from the first calendar year of the date of death. ${ }^{60}$

\section{Conclusion}

Having finished the study of the rights of the decoration designer in the light of Federal Law No. 7 of 2002

\footnotetext{
51 Prof. Nawaf Kanaan, op. Cit., P. 129-130

52 Dr.. Nuri Hamad Khater, A Study on the Jordanian Copyright Law No. 22 of 1992, Mu'tah Magazine for Research and Studies, vol. 12, p /

1,1997 , p. 380 .

53 Prof. Nawaf Kanaan, op. Cit., P. 129-130

54 Youssef Ahmed Nawafla, op. Cit., P. 101, d. Nawaf Kanaan, op. Cit., P. 326.

55 Article $20 / \mathrm{p} 1$ of the Federal Law No. 7 of 2002 on the Protection of Copyright and Neighboring rights.

56 prof. Ali Sayed Kassem, op. Cit., P. 223.

57 Article 20 /p2 of the Federal Law No. 7 of 2002 on the Protection of Copyright and Neighboring rights.

58 prof. Ali Sayed Kassem, op. Cit., P. 223.

59 Article 20 /p3 of the Federal Law No. 7 of 2002 on the Protection of Copyright and Neighboring rights.

${ }^{60}$ Article $20 / \mathrm{p} 1$ of the Federal Law No. 7 of 2002 on the Protection of Copyright and Neighboring rights.
} 
Federal Law No. 7 of 2002 on the Protection of Copyright and Neighboring rights", it was concluded that:

The decoration design has many technical definitions that focused on the element of innovation, which is based on architectural data to bring something new into existence, which is close to the works of art, which needs to be legally protected.

In spite of the great interest of the UAE in the concept of interior design and decoration and the focus of companies that provide interior design services to individuals and companies working in it, such as the interior decoration and finishing works in the local market which became the most active parallel sectors of the construction sector, it was noted in this regard that there is a legislative deficiency in regarding the legal situation of the designers and their artistic products, and their legal responsibility for their mistakes before consumers.

Decoration design is one of the areas of Applied Art. It is intertwined with industrial design, graphic design and fashion design, which reach every place where people live and practice a kind of daily life. It is an extension of the fine architectural design. (Art. 2, paras. 7, 8, 9 and 10, and part of paragraph 11 of the architectural design), and the fact that the UAE legislator has cited the works for examples only but not comprehensively. We have attempted in this study to apply the legal provisions of these works to Decoration Design as a work, and the designer as an author.

\section{Recommendations}

Accordingly, we recommend the Emirati legislator to add the term "Decoration Design" to the works of art mentioned in paragraph 11, article 2, to be included in its legal provisions, as follows: (illustrations, geographical maps, diagrams, three-dimensional works related to geography or topography, architectural designs, decoration designs, etc.). Although interior design is an extension of architectural design, there is a contrast between the function of architectural design and that of interior design, which is more detailed and deeper than the first, - as explained in the search - bearing in mind that we have preferred to mention the term Decoration Design within these works independently to be distinguished from the term Architectural Design.

Due to the importance of the legal aspects of the contracts relating to interior design or decoration, which are related to their legal nature and organization, and the legal relations that arise between designers, whether natural or moral, the owners and engineering consultancy offices, and responsibility arising from errors that may occur when the design is implemented, we found that the Emarati legislator should put in place a legal regulation for Decoration Design among the named contracts. Perhaps this is justified by the fact that the work of interior decoration and finishes in the local market has become one of the most active sectors and parallel to the construction sector in UAE on the one hand,and on the other hand, the legislation governing the construction sector does not address the sector of decoration designs organized by(LEED) System.

\section{Copyrights}

Copyright for this article is retained by the author(s), with first publication rights granted to the journal.

This is an open-access article distributed under the terms and conditions of the Creative Commons Attribution license (http://creativecommons.org/licenses/by/4.0/). 